\section{Impact of gender on influence, power and authoritarianism}

Sangeetha Rajan and

Venkat R. Krishnan

\section{The authors}

Sangeetha Rajan is at $\mathrm{ICICI}$ Bank Limited, Mumbai, India.

Venkat R. Krishnan is at Xavier Labour Relations Institute, Jamshedpur, India.

\section{Keywords}

Gender, Influence, Strategy, Authoritarianism, Managerial power

\section{Abstract}

This paper studies the impact of gender on frequency of use of influence strategies, amount of power and authoritarianism, using a sample of 109 managers from two organizations in India. Seven downward influence strategies (assertiveness, bargaining, coalition, friendliness, higher authority, reason, and sanctions) and five power bases (reward, referent, legitimate, expert, and coercive) were included in the study. Analysis of variance does not show any difference across gender in any variable studied, and analysis of covariance does not reveal any impact of gender on influence and power after controlling for authoritarianism. Results, however, suggest that gender moderates the impact of authoritarianism on influence and power. Authoritarianism is related positively to assertiveness, bargaining, friendliness and legitimate power for men, negatively to coercive power for men, negatively to friendliness for women, and positively to expert power for both men and women. There is a significant interaction effect of authoritarianism and gender on friendliness.

\section{Electronic access}

The research register for this journal is available at http://www.emeraldinsight.com/researchregisters

The current issue and full text archive of this journal is available at http://www.emeraldinsight.com/0964-9425.htm

Women in Management Review

Volume $17 \cdot$ Number $5 \cdot 2002 \cdot$ pp. 197-206

(C) MCB UP Limited · ISSN 0964-9425

DOI $10.1108 / 09649420210433157$

\section{Introduction}

Both women and men are placed in sex-role stereotypes, which influence their personality and behavior patterns. Women are socialized to be passive, accommodative and intuitive, while men are socialized to be aggressive, active and dominating. Gender is thus a variable whose effects cannot be ignored. Demonstrably, women and men differ in their influencing styles and their exercise of power. The relationships between gender and influence and between gender and power are, however, not simple and straightforward but could be modified by several variables.

Authoritarianism captures the core of human personality, and it could therefore be one such moderating variable. However, this area has not been adequately explored. We report here a study that we conducted to look at the impact of gender on influence, power and authoritarianism, and how gender affects the relationships between authoritarianism and amount of power, and between authoritarianism and influence strategies.

\section{Theory and hypotheses}

Successful managers are perceived as being identified more with men than with women in terms of emotional stability, aggressiveness, leadership ability, self-reliance, certainty, vigor, desiring responsibility, seriousness, objectivity, knowledge and straightforwardness. Lyness and Thompson (1997) found that women's jobs had less authority than those of men as measured by the number of subordinates they managed. Women also received fewer stock options, which was viewed as a long-term incentive for retaining managers, suggesting that women were viewed as being less valuable than men. The developmental experiences of women include more non-authority relationships compared with men (Lyness and Thompson, 2000). It would therefore be worth investigating whether women use different influence strategies and tap different bases of power compared with men.

\section{Influence strategies}

Influence is the effect, either intended or unintended, of one party (the agent) on

Received: February 2001

Revised: October 2001

Accepted: November 2001 
another person's (the target's) attitudes, perceptions, behavior or some combination of these outcomes (Yukl, 1998). The essence of managerial work is influencing. Most people, however, do not influence for the sheer joy of changing other people's behavior. They do so with specific reasons in mind. Influence could be used for such personal reasons as securing better work assignments, or for such organizational reasons as introducing new work procedures, the latter being more common (Yukl and Tracey, 1992). Attempts have been made to classify influence tactics in categories like rational persuasion and ingratiation (Kipnis and Schmidt, 1988; Schilit and Locke, 1982; Yukl et al., 1996). Kipnis et al. (1980) identified and classified examples of behavioral tactics used to influence superiors, peers and subordinates. An inductive method was used based on responses from organization members, and the tactics used to influence subordinates were grouped into the following seven influence strategies:

(1) Assertiveness. Demanding compliance, ordering, setting deadlines, nagging and expressing anger.

(2) Bargaining. Offering to help others in exchange for reciprocal favors.

(3) Coalition. Building alliances with others.

(4) Friendliness. Praising, politely asking, acting humbly, making the other person feel important and acting in a friendly manner.

(5) Higher authority. Appealing to those higher in the hierarchy.

(6) Reasoning. Using reason and logic, and convincing others that certain actions are in their own best interests.

(7) Sanctions. Using the power inherent in the organization to back up one's requests (Kipnis et al., 1980).

Success is more likely when a combination of several influence strategies is used (Gupta and Case, 1999). People tend to use different influence strategies depending on whether their goals are personal or organizational, and depending on the organizational climate (Schmidt and Kipnis, 1984). For example, individuals working in a rational organizational climate would more frequently use strategies like reasoning (Cheng, 1983). Similarly, the characteristics of the target person also affect the choice of influence strategies. Followers use reasoning strategy more frequently to influence participative than autocratic leaders (Ansari and Kapoor, 1987). Frequency of use of higher authority, coalition and assertiveness strategies is negatively related to the quality of relationship between the influencing agent and the target (Deluga and Perry, 1991). Choice and frequency of use of influence strategies are also related to an individual's beliefs, attitudes and traits. Blickle (2000) found that work values predicted the frequency of use of influence strategies measured one year later.

\section{Power}

Power is the capacity to influence others (Yukl, 1998). Burns (1978) viewed power as a function of the motives of both the power-holder and the recipient. Power is a manifestation of an asymmetry in the relationship between two people. French and Raven (1959) identified five types or bases of power:

(1) coercive;

(2) reward;

(3) legitimate;

(4) expert; and

(5) referent.

A major criticism of the French and Raven typology is that the power bases lack conceptual consistency regarding the source or origin (Hinkin and Schriesheim, 1989). For example, the source of reward power is the power-holder's ability to administer outcomes that are rewarding, while the source of referent power is the person's perceived attractiveness. Hinkin and Schriesheim (1989) constructed a new measure of the five bases that is more psychometrically sound than the previously used single item measures. They also redefined the five bases of power so that they are more conceptually consistent, in terms of all the five bases involving the ability to administer tangible or intangible outcomes.

Influence is the exercise of power. Brass and Burkhardt (1993) found that power, as measured by formal hierarchical level in the organization, was positively related to the influence strategies of assertiveness and exchange. Yukl et al. (1996) found that referent power, which is based on personal attraction, was negatively related to pressure tactics. People also resort to greater use of influence strategies when existing sources of power become unavailable (Westphal, 1998). 
Power, besides directly affecting the use of influence strategies, might also affect the relationship between personality traits and use of influence strategies.

\section{Authoritarianism}

For over 50 years, the concept of authoritarianism has provided a framework for analyzing relationships between personality and a variety of social and political issues. Leaders who are highly authoritarian tend to interact with others in ways that are different from those used by less authoritarian leaders. The influencing mechanisms to which they resort are not only limited in range but also impersonal.

Adorno et al. (1950) postulated a personality type termed authoritarian that was characterized as:

- politically and religiously conservative;

- emotionally cold;

- power-seeking;

- hostile towards minority groups;

- resistant to change; and

- opposed to humanitarian values.

Authoritarianism has three basic components:

(1) conventionality;

(2) acceptance of authority or authoritarian submission; and

(3) authoritarian aggression (Doty et al., 1997).

These three may arise from a basic sense of threat that arouses intolerance of ambiguity, which leads to a sharp differentiation between the good and the bad, and ultimately permits the good to punish the bad. Threat is an important antecedent of authoritarianism (Duncan et al., 1997). The main criticisms surrounding the original concept were mainly about the validity of the instrument used to measure it, namely, the $F$-scale developed by Adorno et al. (1950). Scores on the F-scale could be primarily explained by the response set of social acquiescence - the tendency to agree with statements of attitudes, since all items were written in the same power-oriented terms (Verkuyten and Hagendoorn, 1998). However, opinions on this count have remained contradictory. Additionally, other scales that measure similar dimensions have been developed.

Personality traits are related to use of influence strategies. Kipnis and Schmidt (1988) classified individuals into four groups based on their use of various influence strategies. Dustin and Davis (1967) found that authoritarian individuals used negative sanctions (monetary penalties and negative evaluation) significantly more often than egalitarians. It has also been found that the authoritarianism of chief petty officers is positively related to the number of demerits given to recruits (Bass, 1990). Authoritarian leaders would tend to make less use of the soft influence strategies like friendliness and more of the hard influence strategies. Hence, we hypothesized:

H1. Authoritarianism would be positively related to the frequency of use of assertiveness and sanctions.

Duncan et al. (1997) held that a tendency exists on the part of high authoritarian individuals to organize the world in terms of power hierarchies or hegemonies. Specifically, people are categorized as belonging to in-groups and out-groups, which are respectively viewed as sources of traditional authority and challenge to that authority. Hegemonies could be based on race, ethnicity, sexual orientation and gender. Authoritarianism is positively related to discrimination exhibited towards out-group members (Petersen and Dietz, 2000). Studies have found that authoritarian individuals are more sensitive to the rank of a leader than egalitarians. They also tend to become more submissive when faced with a high status instigator, but reject the efforts of a low status instigator. In addition, while egalitarians are more sensitized to differences in personal power and to behavioral cues, authoritarian individuals tend to differentiate in terms of institutional status (Bass, 1990). Thus, position seems to be central to the authoritarian personality, and it would therefore determine largely the individual's interactions with the world, including perhaps the way influence is exercised. The two bases of power that are most relevant to the authoritarian personality are legitimate and coercive.

\section{Legitimate power}

Authority or position power was defined as legitimate power by French and Raven (1959). Power derived from one's position requires the consent or acceptance of the power recipients (Pfeffer, 1992). The acceptance of hierarchy or the chain of command could be due to several reasons like believing that the power-holder knows better, 
preventing ambiguity, or simply because it is inconceivable not to obey authority. Hinkin and Schriesheim (1989) defined legitimate power as the ability to administer to another feelings of obligation or responsibility.

\section{Coercive power}

Coercive power implies the ability to impose penalties for non-compliance (Bass, 1990).

Hinkin and Schriesheim (1989) defined coercive power as the ability to administer to another things he or she does not desire and remove or decrease things he or she does desire. Greene and Podsakoff (1981) demonstrated that leaders were more inclined to use coercive power when they were under pressure to maintain high-productivity deadlines, and had lost their power to reward good performance. When an influencing agent has coercive power and uses it, then the agent would tend to diminish and distrust the target. This results in part from the fact that coercive power requires surveillance, due to which the target is judged as unworthy (Raven, 1993).

Authoritarian leaders are more likely to rely on power that is a result of the hierarchical position they hold than on any other type of power. That is, legitimate and coercive power would be more relevant to authoritarian leaders than other bases of power. The relationship between authoritarianism and use of influence strategies could also be affected by legitimate power and coercive power, the two bases of power that are most relevant to authoritarianism. Hence:

H2. Authoritarianism would be positively related to legitimate and coercive power.

H3. Legitimate power would moderate the relationship between authoritarianism and frequency of use of assertiveness.

H4. Coercive power would moderate the relationship between authoritarianism and frequency of use of sanctions.

Duncan et al. (1997) conceptualized gender in terms of a hegemonic relationship, and found evidence, which suggests that those scoring high on authoritarianism were inclined to maintain traditional gender roles and demonstrated a rejection of non-traditional gender-role identity. In fact, other studies have shown that authoritarianism is related to support of traditional gender role ideology (Walker $e t$ al., 1993). Therefore, authoritarian women would want to abide by traditional gender norms, and would not be inclined to use legitimate and coercive power. They would also not use assertiveness and sanctions to influence others. Authoritarian men, on the other hand, would preserve traditional sex role stereotypes and would tend even more to subscribe to these bases of power and to use these tactics. We therefore hypothesized:

H5. Gender would moderate the relationship between authoritarianism and the frequency of use of assertiveness and sanctions strategies.

H6. Gender would moderate the relationship between authoritarianism and the amount of legitimate power and coercive power.

\section{Method}

\section{Sample}

The sample comprised 109 respondents (74 males and 35 females) from the managerial cadre of two Indian companies. The first company is a monopoly service provider to the exporting community with branches all over the world. The study was conducted across three of their offices in a metropolitan city situated in western India. The second company is a mid-sized corporation that manufactures steel and steel products in India. Both companies have comparable and tall hierarchies. The respondents were all from any of five hierarchical levels and well educated (that is, Bachelor's degree or more). The average age of respondents was 43 years. They had an average of six people reporting to them, had spent an average of 18 years with their organizations, and had an average of 21 years of total work experience.

\section{Measures}

The final version of the $F$-scale (Adorno et al., 1950) was used to measure authoritarianism. All the items in the final version were included in this study with the exception of one item ("It is best to use some pre-war authorities in Germany to keep order and prevent chaos"), which was not considered relevant in the Indian context. The managers responded to the 30 items using a 5 -point scale $(1=$ strongly disagree; 2 = disagree; $3=$ neither agree nor disagree; $4=$ agree; $5=$ strongly agree). Three of the dimensions 
were excluded from the analysis, as their reliabilities (Cronbach alpha) for our sample were low (superstition $=0.37$; destructivenes $=0.28$; sex $=0.25)$. The scores for the remaining six dimensions, viz.

conventionalism, authoritarian submission, authoritarian aggression, anti-intraception, power and toughness, and projectivity (with alphas of $0.57,0.60,0.75,0.43,0.62$, and 0.52 respectively) were calculated by taking the mean of items comprising each dimension. Before aggregating the six dimensions two unreliable items were dropped from conventionalism and two from anti-intraception. The mean of the six dimensions was taken as the authoritarianism score, as their inter-correlations were high ( $r$ ranging from 0.36 to 0.83 with $p<0.001$ ).

The profiles of organizational influence strategies (POIS) Form S (Kipnis and Schmidt, 1982), consisting of 33 items, was used to measure the frequency with which managers (respondents) used the seven influence strategies with respect to their subordinates. Assertiveness had seven, bargaining five, coalition two, friendliness six, higher authority four, reasoning four, and sanctions five items. Each item represented an influence tactic, and respondents were asked to indicate on a fivepoint scale $(1=$ never; $2=$ seldom; 3 = occasionally; $4=$ frequently $5=$ almost always) how often they generally used each of the 33 tactics.

The five bases of power were measured using the scale developed by Hinkin and Schriesheim (1989). This scale was preferred over the single item measures that were previously used because of the conceptual consistency underlying the definitions that were used in its development and because this scale is psychometrically stronger. The scale has 20 items (four items for each power base), and the managers responded to the items using a 5-point scale ( 1 = strongly disagree; $2=$ disagree; $3=$ neither agree nor disagree; $4=$ agree; 5 = strongly agree).

The five bases of power rather than network centrality have been used as a measure of power, as the relevance of these dimensions to authoritarianism has been demonstrated. The items on the scale were modified to make them suitable for self-rating. The number of items and the dimensions were, however, retained.

\section{Results}

The means, standard deviations, reliabilities (Cronbach alphas) for the influence and power variables, and correlation coefficients between all variables are provided in Table I. The first hypothesis was partly supported. Authoritarianism was significantly positively correlated with assertiveness $(r=0.29$, $p<0.01$ ), but it was not significantly correlated with sanctions. There was also a significant positive correlation between sanctions and assertiveness $(r=0.26$, $p<0.01)$.

The second hypothesis was partially supported. Legitimate power was significantly positively correlated with authoritarianism ( $r=0.27, p<0.01$ ), but coercive power was, contrary to what we had hypothesized, significantly negatively correlated $(r=-0.25$, $p<0.01)$. Additionally, authoritarianism was significantly positively correlated with expert power $(r=0.40, p<0.001)$. Legitimate power was significantly and positively related to reward power, referent power, and expert power, and significantly negatively related to coercive power.

We also found some significant $(p<0.05)$ relationships between the seven influence strategies and the five bases of power.

Legitimate power, expert power, and referent power were all negatively related to sanctions and higher authority, and positively related to reason. Coercive power was positively related to bargaining, coalition and friendliness.

Reward power was positively related to bargaining. None of the five bases of power was related to assertiveness.

$H 3$ and $H 4$ were tested using partial correlation analysis. For $H 3$, we looked at the correlation between assertiveness and the product of authoritarianism and legitimate power after controlling for authoritarianism and legitimate power. The partial correlation coefficient was not significant and therefore our H3 was not supported. Legitimate power did not moderate the relationship between authoritarianism and assertiveness. A similar treatment was given to $H 4$, by controlling for authoritarianism and coercive power, and correlating their product with sanctions. Here, the partial correlation was significant (partial $r=-0.31, p<0.01$ ), thus supporting the hypothesis. Coercive power moderated the relationship between authoritarianism and frequency of use of sanctions strategy. 


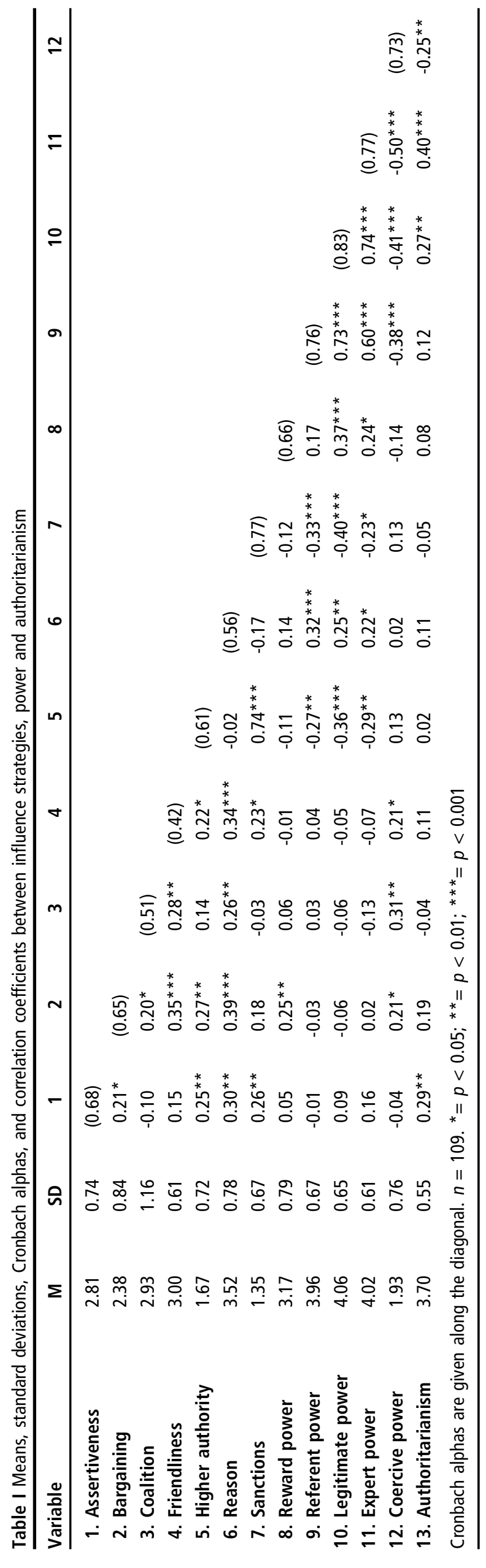


We did an analysis of variance to test whether frequency of use of influence strategies, amount of power, and authoritarianism varied across genders. No significant gender differences were found in any of the variables. We also looked at the correlations between authoritarianism and influence and authoritarianism and power for either gender separately. The results of analysis of variance and correlation coefficients by gender are provided in Table II. In the case of men, authoritarianism was significantly positively related to assertiveness, bargaining and legitimate power and significantly negatively related to coercive power, while there were no such relationships in the case of women. Gender thus moderated the impact of authoritarianism on assertiveness, legitimate power and coercive power, but not on sanctions. Our $\mathrm{H} 5$ was therefore supported in the case of assertiveness, but not in the case of sanctions. $H 6$ on legitimate power and coercive power was supported. Only the relationship between authoritarianism and expert power, found significant and positive in the overall sample, continued to exist when analyzed separately for either gender. The correlation between authoritarianism and friendliness was positive for men and negative for women ( $p<0.10$ for both).

We did an analysis of covariance to see whether influence strategies and power bases varied across genders after controlling for authoritarianism. Analysis of covariance assumes that the slope of the covariate by independent variable is the same for all levels of the independent variable (Scheffe, 1959).
We tested for heterogeneity of slopes by modeling each influence strategy and power base separately against authoritarianism, gender and the product of authoritarianism and gender. The interaction of gender and authoritarianism was significant in the case of friendliness (product term's mean square $=$ $1.73, F$ value $=4.66, p<0.05)$. Gender thus moderated the relationship between authoritarianism and friendliness, with authoritarian men using friendliness more frequently and authoritarian women using it less frequently. Except in the case of friendliness, there was no significant difference in the authoritarianism by gender relationship as a function of gender. We therefore did the analysis of covariance except in the case of friendliness. The least square means of none of the variables significantly differed across the genders. There was thus no difference in influence strategies and power bases across genders even after controlling for authoritarianism.

\section{Discussion}

While there are no gender differences in any of the variables studied, there are differences in the strength of relationships between authoritarianism and power and between authoritarianism and influence for men and women. Authoritarianism is related positively to legitimate power and negatively to coercive power for men, but not for women. In the case of influence strategies, authoritarianism is related positively to assertiveness and

Table II Analysis of variance and correlations with authoritarianism by gender

\begin{tabular}{lccccc}
\hline & \multicolumn{2}{c}{ Mean } & \multicolumn{3}{c}{ Correlation with authoritarianism } \\
& Men & Women & F value & Men & Women \\
\hline Assertiveness & 2.81 & 2.80 & 0.01 & $0.36^{* *}$ & 0.10 \\
Bargaining & 2.41 & 2.34 & 0.16 & $0.28^{*}$ & -0.11 \\
Coalition & 2.85 & 3.09 & 0.97 & -0.08 & 0.06 \\
Friendliness & 3.02 & 2.95 & 0.32 & $0.21 \$$ & $-0.30 \$$ \\
Higher authority & 1.62 & 1.77 & 1.01 & 0.05 & -0.12 \\
Reason & 3.55 & 3.44 & 0.55 & 0.12 & 0.17 \\
Sanctions & 1.35 & 1.35 & 0.00 & -0.01 & -0.16 \\
Reward power & 3.15 & 3.23 & 0.29 & 0.04 & 0.21 \\
Referent power & 4.01 & 3.83 & 1.74 & 0.14 & 0.18 \\
Legitimate power & 4.10 & 3.99 & 0.72 & $0.33^{* *}$ & 0.18 \\
Expert power & 4.04 & 3.96 & 0.47 & $0.44^{* * *}$ & $0.32 \$$ \\
Coercive power & 1.98 & 1.84 & 0.71 & $-0.30^{*}$ & -0.05 \\
Authoritarianism & 3.65 & 3.82 & 2.08 & & \\
$n=74$ for men, 35 for women. $\$=p<0.10 .{ }^{*}=p<0.05 ; * *$ & $p<0.01 ; * * *$ & $p<0.001$ & \\
\hline
\end{tabular}


bargaining for men, but not for women.

Authoritarianism is also related positively to friendliness for men, while it is related negatively to friendliness for women.

\section{Authoritarianism and power}

The positive relationship between authoritarianism and legitimate power for men is consistent with earlier research findings (Duncan et al., 1997; Thibaut and Riecken, 1955). Authoritarian men are possibly status-conscious, and therefore legitimate power could be important for them. Legitimate power is handed to organizational members by a higher authority and, given that it would be this type of power that they would consider indicative of status, they might be more willing to declare it. Authoritarian women, on the other hand, might want to conform to gender stereotypes and not highlight their status. Therefore, authoritarianism is not related to legitimate power in the case of women.

A surprising finding of our study is the negative relationship between authoritarianism and coercive power in the case of men. There are several possible explanations for this. It is possible that authoritarian men are high on external locus of control. In addition, a superstitious inclination is part of the authoritarian personality structure, and the concept of authoritarianism includes one dimension related to superstition (Adorno et al., 1950). High authoritarian men might therefore attribute less coercive power to themselves than low authoritarian men. They might prefer to put the onus of any coercive power on the institution to which they belong and on the rules of that institution rather than to accept responsibility for it. Authoritarian women, on the other hand, may not want to disown their coercing capabilities, and therefore coercive power is not related to authoritarianism in the case of women. A possible explanation for this is also that high-authoritarian women are more reluctant than high-authoritarian men to acknowledge coercive power, which is consistent with previous findings (Duncan et al., 1997).

Additionally, social desirability appears to be far more important for authoritarian men than women. Given the emphasis in today's workplace on using non-coercive methods of getting work done, authoritarian men might be concerned about doing what is institutionally correct. They might therefore mark a low response for statements such as: ... can make things unpleasant here

or:

... can make work distasteful

etc. However, social desirability does appear to affect both men and women, as the mean score for coercive power was low for all respondents (1.93).

Authoritarianism is positively correlated to expert power for both men and women. Among the five bases of power, expert power is the one that is most strongly related to authoritarianism. The high positive correlation between legitimate and expert power also suggests that a means to acquiring legitimate power could be expert power. A possible explanation for this is that status is important to authoritarian leaders, and the means for acquiring status in these organizations is inextricably tied to performance in a given technical area.

The implications of these results could range from the roles that ideally should be assigned to authoritarian people in teams, to designing reward and promotion structures in organizations. It also has implications specifically for the development of authoritarian men in organizations. They are probably comfortable acknowledging power that is officially handed down to them, but are not comfortable with power that they have to acquire actively. This is evidenced by the fact that, while legitimate power is significantly positively correlated to reward power and referent power, authoritarianism is correlated to only legitimate power. In order to change their styles of managing people, therefore, they need to be made more explicitly aware of other bases of power also.

\section{Authoritarianism and influence strategies}

A significant finding of the study is that authoritarianism is related positively to friendliness for men, while it is related negatively to friendliness for women.

Authoritarian men tend to use the strategy of friendliness more frequently, while authoritarian women are likely to use friendliness less frequently. Authoritarian women might simply use strategies that are consistent with their personality style and therefore end up using less of friendliness. Authoritarian men, on the other hand, might 
want to play down their authoritarian nature by using friendliness strategy more frequently. It appears that, while authoritarian men do not have a problem in doing things that are inconsistent with their basic personality structure, authoritarian women seem to be more inclined to be consistent.

In the case of men, authoritarianism is positively related to frequency of use of assertiveness and bargaining strategies, but it is not related to frequency of use of sanctions. It is possible that people in general, whether authoritarian or not, are averse to using sanctions, as the mean score for sanctions was very low for both men and women (1.35). Authoritarian men might prefer to use assertiveness and bargaining more frequently, because they probably identify themselves with institutional authority and do not see the need for any other influence strategy with respect to their subordinates. Highauthoritarian women, on the contrary, might conform with gender stereotypes and might therefore desist from using assertiveness and bargaining more frequently.

The implications are that, in an organization that is moving toward a more participative climate, allowing highly authoritarian men to influence people in the way that they are naturally inclined could be dysfunctional. There is a positive correlation between authoritarianism and assertiveness for men, but legitimate power does not have any effect on the relationship between authoritarianism and assertiveness.

Authoritarian men are likely to use assertiveness with their subordinates irrespective of the degree of relative positional power granted to them. This may lead to unfavorable outcomes when influencing a target who sees the leader demanding compliance without the authority to do so in a work scenario where adult-adult relationships are being increasingly emphasized.

Since high authoritarian women (and men) tend to conform with gender stereotypes in influencing people and in acknowledging their power bases, authoritarianism is a factor that would have to be taken into account when conducting assertiveness training programs for women. They could be particularly resistant to change in that direction, if their unwillingness to be assertive is due to a basic personality structure. Conversely, there could be resistance from authoritarian men, who would not want to espouse a "soft" leadership style, as it would be disharmonious with the conventional male stereotype.

\section{Limitations of the study}

Participation in the study was voluntary and, possibly, there was some bias in terms of self-selection. The assumption in the use of the $F$-scale is that authoritarianism is a relatively enduring personality characteristic. It is also possible that it is a pattern of behavior that is situationally influenced, in which case the implications of the study would change considerably. Understanding the moderating effect of gender probably requires a larger sample of women. Therefore, while the findings of this study are quite reliable for this sample, its generalizability is limited.

\section{Directions for future study}

The study could be extended to companies that have relatively flat hierarchies, that are fast-moving and new age, such as information technology companies, so that implications that are more meaningful can be derived for the working of teams. It would also probably be relevant to study the concept of authoritarianism with other variables such as willingness to change and tolerance of ambiguity, as these would be relevant in today's workplace. Extending the study to upward influence styles as well as peer influence styles might also help complete an understanding of the way authoritarianism relates to power and influence.

\section{Conclusion}

This study looked at the sources of power that authoritarian men and women tap, and the influence strategies that they use. Authoritarian men are more likely to tap legitimate power but not coercive power. Authoritarian men use assertiveness, bargaining and friendliness strategies more frequently than authoritarian women. Overall, the findings suggest that gender and personality combine to affect power and influence. Thus, ignoring gender and studying the effect of only personality on power and influence may not present an accurate picture. Power and influence form the crux of managerial functioning. As further studies provide additional support by looking at more personality dimensions, use of power and influence by both men and women would be better understood. 


\section{References}

Adorno, T.W., Frenkel-Brunswik, E., Levinson, D.J. and Sanford, R.N. (1950), The Authoritarian Personality, Harper \& Row, New York, NY.

Ansari, M.A. and Kapoor, A. (1987), "Organizational context and upward influence tactics", Organizational Behavior and Human Decision Processes, Vol. 40, pp. 39-49.

Bass, B.M. (1990), Bass and Stogdill's Handbook of Leadership: Theory, Research, and Managerial Applications, The Free Press, New York, NY.

Blickle, G. (2000), "Do work values predict the use of intra-organizational influence strategies?", Journal of Applied Social Psychology, Vol. 30 No. 1, pp. 196-205.

Brass, D.J. and Burkhardt, M.E. (1993), "Potential power and power use: an investigation of structure and behavior", Academy of Management Journal, Vol. 36, pp. 441-70.

Burns, J.M. (1978), Leadership, Harper \& Row, New York, NY.

Cheng, J.L.C. (1983), "Organizational context and upward influence: an experimental study of the use of power tactics", Group and Organization Studies, Vol. 8, pp. 337-55.

Deluga, R.J. and Perry, J.T. (1991), "The relationship of subordinate upward influencing behaviour, satisfaction and perceived superior effectiveness with leader-member exchanges", Journal of Occupational Psychology, Vol. 64 No. 3, pp. 239-52.

Doty, R.M., Winter, D.G., Peterson, B.E. and Kemmelmeier, M. (1997), "Authoritarianism and American students' attitudes about the gulf war", Personality and Social Psychology Bulletin, Vol. 23 No. 11, pp. 1133-43.

Duncan, L.E., Peterson, B.E. and Winter, D.G. (1997), "Authoritarianism and gender roles: toward a psychological analysis of hegemonic relationships", Personality and Social Psychology Bulletin, Vol. 23 No. 1, pp. 41-9.

Dustin, D.S. and Davis, H.P. (1967), "Authoritarianism and sanctioning behavior", Journal of Personality and Social Psychology, Vol. 6, pp. 222-4.

French, J.P. and Raven, B. (1959), "The bases of social power", in Cartwright, D. and Zander, A. (Eds), Group Dynamics, Harper \& Row, New York, NY, pp. 150-67.

Greene, C.N. and Podsakoff, P.M. (1981), "Effects of withdrawal on a performance-contingent reward on supervisory influence and power", Academy of Management Journal, Vol. 24, pp. 527-42.

Gupta, S. and Case, T.L. (1999), "Managers' outward influence tactics and their consequences: an exploratory study", Leadership \& Organization Development Journal, Vol. 20 No. 6, pp. 300-8.

Hinkin, T.R. and Schriesheim, C.A. (1989), "Development and application of new scales to measure the French and Raven (1959) bases of social power", Journal of Applied Psychology, Vol. 74, pp. 561-7.

Kipnis, D. and Schmidt, S.M. (1982), Profiles of Organizational Influence Strategies (Form S), University Associates, San Diego, CA.
Kipnis, D. and Schmidt, S.M. (1988), "Upward-influence styles: relationship with performance evaluations, salary, and stress", Administrative Science Quarterly, Vol. 33, pp. 528-42.

Kipnis, D., Schmidt, S.M. and Wilkinson, I. (1980), "Intra-organizational influence tactics: explorations in getting one's way", Journal of Applied Psychology, Vol. 65, pp. 440-52.

Lyness, K.S. and Thompson, D.E. (1997), "Above the glass ceiling? A comparison of matched samples of female and male executives", Journal of Applied Psychology, Vol. 82, pp. 359-75.

Lyness, K.S. and Thompson, D.E. (2000), "Climbing the corporate ladder: do female and male executives follow the same route?", Journal of Applied Psychology, Vol. 85, pp. 86-101.

Petersen, L. and Dietz, J. (2000), "Social discrimination in a personnel selection context: the effects of an authority's instruction to discriminate and followers' authoritarianism", Journal of Applied Social Psychology, Vol. 30 No. 1, pp. 206-20.

Pfeffer, J. (1992), Managing with Power: Politics and Influence in Organizations, Harvard Business School Press, Boston, MA.

Raven, B.H. (1993), "The bases of power: origins and recent developments", Journal of Social Issues, Vol. 49 No. 4, pp. 227-51.

Scheffe, H. (1959), The Analysis of Variance, John Wiley, New York, NY.

Schilit, W.K. and Locke, E.A. (1982), "A study of upward influence in organizations", Administrative Science Quarterly, Vol. 27, pp. 304-16.

Schmidt, S.M. and Kipnis, D. (1984), "Managers' pursuit of individual and organizational goals", Human Relations, Vol. 37, pp. 781-94.

Thibaut, J.W. and Riecken, H.W. (1995), "Authoritarianism, status and the communication of aggression", Human Relations, Vol. 8, pp. 95-120.

Verkuyten, M. and Hagendoorn, L. (1998), "Prejudice and self-categorization: the variable role of authoritarianism and in-group stereotypes", Personality and Social Psychology Bulletin, Vol. 24 No. 1, pp. 99-110.

Walker, W.D., Rowe, R.C. and Quinsey, V.L. (1993), "Authoritarianism and sexual aggression", Journal of Personality and Social Psychology, Vol. 65, pp. 1036-45.

Westphal, J.D. (1998), "Board games: how CEOs adapt to increases in structural board independence from management", Administrative Science Quarterly, Vol. 43, pp. 511-37.

Yukl, G. (1998), Leadership in Organizations, 4th ed., Prentice-Hall, Englewood Cliffs, NJ.

Yukl, G. and Tracey, J.B. (1992), "Consequences of influence tactics used with subordinates, peers, and the boss", Journal of Applied Psychology, Vol. 77, pp. 525-35.

Yukl, G., Kim, H. and Falbe, C.M. (1996), "Antecedents of influence outcomes", Journal of Applied Psychology, Vol. 81, pp. 309-17. 